\title{
EKOLOGI, KERUGIAN, DAN PENGELOLAAN GULMA JAJAGOAN (Echinochloa crus-galli) RESISTEN HERBISIDA PADA PERTANAMAN PADI SAWAH: REVIEW
}

\author{
Koko Tampubolon* \\ Program Studi Agroteknologi, Fakultas Pertanian dan Peternakan, Universitas Tjut Nyak Dhien, Medan \\ 20123, Sumatera Utara, Indonesia. Email: koko.tampubolon@gmail.com

\begin{abstract}
Alridiwirsah
Program Studi Agroteknologi, Fakultas Pertanian, Universitas Muhammadiyah Sumatera Utara, Medan 20238, Sumatera Utara, Indonesia.
\end{abstract} \\ Novilda Elizabeth Mustamu \\ Program Studi Agroteknologi, Fakultas Sains dan Teknologi, Universitas Labuhanbatu, Rantauprapat \\ 21418, Sumatera Utara, Indonesia.
}

\begin{abstract}
Abstrak
Gulma jajagoan (Echinochloa crus-galli) dapat menyebabkan penurunan produksi padi sawah dan sudah dilaporkan resisten terhadap beberapa herbisida. Tujuan review artikel ini sebagai informasi awal yang dapat dijadikan alternatif pengendalian gulma jajagoan (E. crus-galli) yang sudah mengalami resisten herbisida pada areal pertanaman padi sawah. Hasil review menginformasikan bahwa gulma E. crus-galli tergolong toleran pada berbagai kondisi iklim, memiliki jumlah biji yang melimpah mengakibatkan populasinya selalu hadir di areal persawahan dan menimbulkan kerugian produksi padi sawah jika tidak dikendalikan, bahkan gulma ini sudah resisten terhadap beberapa herbisida. Upaya pengelolaan gulma E. crus-galli resisten-herbisida menyarankan menggunakan mode of action herbisida baik secara tunggal atau campuran sebagai manajemen resisten dan diharapkan dapat memutus siklus resisten di areal persawahan.
\end{abstract}

Kata Kunci: gulma jajagoan, mode of action herbisida, pengendalian, resisten

\section{PENDAHULUAN}

Produksi beras di Indonesia mencapai 49,81 juta ton dengan konsumsi 111,58 kg/kapita/tahun (Pusat Data dan Sistem Informasi Pertanian, 2019). Kebutuhan beras ini dikhawatirkan kurang mampu mencukupi seiring dengan peningkatan jumlah penduduk di Indonesia. Hal ini disebabkan menurunnya produksi padi sawah dikarenakan kurangnya pengelolaan gulma yang tepat, salah satunya gulma penting yaitu jajagoan.

Gulma jajagoan (Echinochloa crus-galli L.) merupakan gulma yang sangat kompetitif dengan pertanaman padi sawah dikarenakan produksi biji yang banyak, pertumbuhan yang cepat dan memiliki jalur fotosintesis C4 (Marambe \& Amarasinghe, 2002). Kerugian yang ditimbulkan jika gulma ini tidak dikendalikan dapat menurunkan produksi padi sawah sekitar 30\% (Marchesi \& Chauhan, 2019); menurunkan bobot gabah isi padi sebesar 46,20\% (Guntoro et al., 2009), dan menurunkan produksi padi berkisar 57-95\% (Ahn \& Chung, 2000). Upaya pengendalian gulma ini yang sering dilakukan petani padi sawah adalah penyemprotan herbisida sintesis (kimiawi), seperti herbisida 2,4-D dimetil amina. Namun penggunaan herbisida sintesis ini secara berkelanjutan dan terus menerus akan menimbulkan permasalahan baru yaitu kekebalan (resisten) gulma terhadap herbisida (Purba, 2009). Telah dilaporkan bahwa gulma E. crus-galli dari pertanaman padi sawah telah resisten herbisida fenoxaprop-p-etil, imazamox, imazethapyr, propanil, quinclorac di Mississippi (Heap, 2015); resisten herbisida molinate, thiobencarb, fenoxaprop-etil, natrium bispiribak (Fischer et al., 2000). resistensi ganda terhadap herbisida quinclorac, penoxsulam, cyhalofopbutil (Eberhardt et al., 2016); resisten-imidazolinon (Matzenbacher et al., 2013) dan resisten-quinclorac di Cina (Li et al., 2016; Yang et al., 2017; Zhu et al., 2018).

Berdasarkan kasus resistensi diatas, dibutuhkan referensi yang komplek untuk mengkaji ekologi gulma jajagoan (E. crus-galli), seberapa besar kerugian yang ditimbulkannya, laporan kasus resistensi gulma ini, serta pengelolaan resisten yang tepat untuk dilakukan di areal pertanaman padi sawah. Tujuan review artikel ini sebagai informasi awal yang dapat dijadikan alternatif pengendalian gulma jajagoan (E. crus-galli) yang sudah mengalami resisten herbisida pada areal pertanaman padi sawah.

\section{HASIL REVIEW}

\section{Ekologi Gulma Jajagoan}

Gulma jajagoan (E. crus-galli) berasal dari Eropa dan telah menyebar di seluruh dunia termasuk Asia, Australia, dan Amerika (Carey et al., 1995; Van Devender et al., 1997; Gealy et al., 2003). Gulma ini memiliki kemampuan kompetitif dan karakteristik adaptif untuk bertahan hidup pada berbagai kondisi iklim dan geografis (Marambe \& Amarasinghe, 2002). Gulma ini termasuk gulma berhari pendek, musiman, dan gulma tropis (Chin, 2001; Rao et al., 2007; Juliano et al., 2010) dan dapat menyesuaikan dengan suhu dan kelembaban yang beragam dalam menyelesaikan siklus hidup (Maun \& Barrett, 1986; Gallandt, 2006). Benih E. crus-galli dapat berkecambah pada berbagai suhu dari $13-40^{\circ} \mathrm{C}$, dan 
terdapat hubungan linier antara suhu dan perkecambahan (Alvarado \& Bradford, 2002). Karakter morfologis, fisiologis, dan biokimiawi gulma ini menjadikan pesaing kuat pada areal tanaman padi sawah maupun tanaman lainnya (Maun \& Barrett, 1986; Clay et al., 2005). Gulma E. crus-galli dapat menghasilkan biji dalam jumlah banyak dan memiliki tingkat dormansi biji yang meningkatkan seedbank didalam tanah (Gibson et al., 2002; Clay et al., 2005). Karakteristik gulma E. crusgalli dapat dilihat pada Gambar 1.

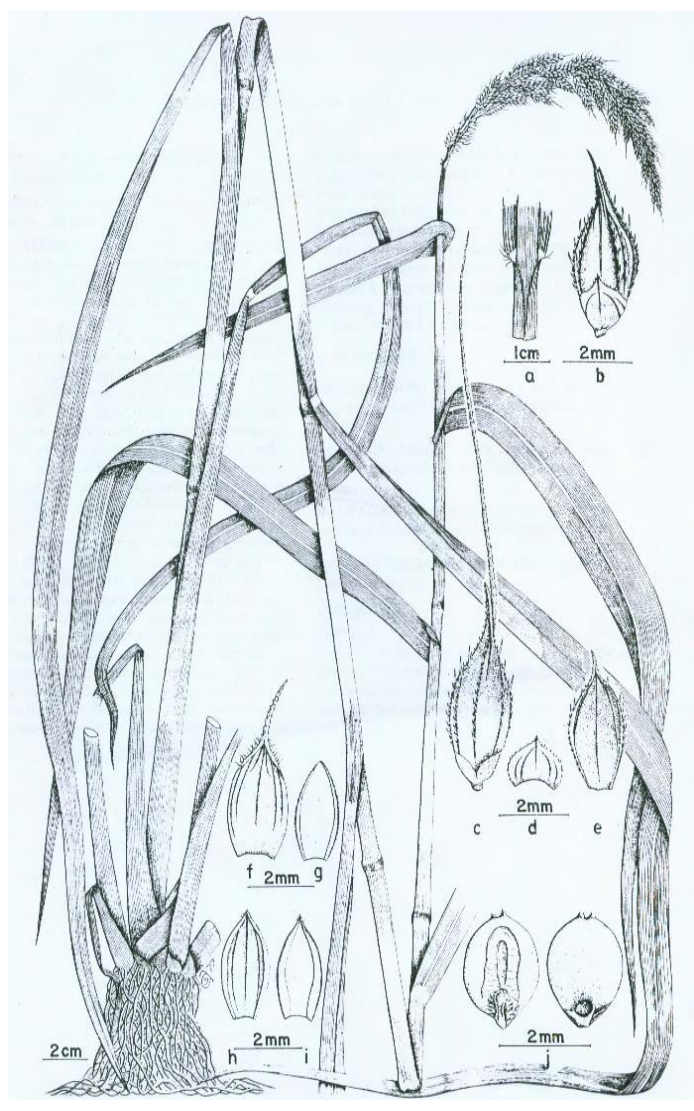

Gambar 1. Gulma Echinochloa crus-galli (L.) Beauv. Sumber: Soerjani et al., (1987).

\section{Kerugian Tanaman Padi Sawah Akibat Gulma Jajagoan}

Kerapatan 10 populasi gulma E. crus-galli per $\mathrm{m}^{2}$ dapat menghasilkan 34.600 biji (Travlos et al., 2011). Rataan suhu berkisar dari $28-30^{\circ} \mathrm{C}$ menjadikan E. crusgalli mampu mengakumulasi bobot kering lebih banyak dibandingkan tanaman padi sawah. Keberadaan satu populasi E. crus-galli pada jarak $40 \mathrm{~cm}$ dari tanaman padi dapat mengurangi hasil panen sebesar $27 \%$. Infestasi $E$. crus-galli yang lebih tinggi dapat menyerap ketersedian nitrogen sebesar $60-80 \%$ dan menghambat pertumbuhan tanaman (Wilson et al., 2014). Gulma E. crus-galli telah dilaporkan dapat menurunkan produksi padi sebesar 30$100 \%$ secara global sepanjang musim tanam padi (Singh et al., 2015; Bhullar et al., 2016; Marchesi et al., 2019). Gulma E. crus-galli dapat menyebabkan penurunan hasil gabah padi mencapai 61\% (Saito et al., 2010) dan dapat menurunkan jumlah daun, jumlah anakan produktif, bobot kering akar, panjang daun, luas daun bendera, dan produksi tanaman padi sawah (Guntoro et al., 2009).

\section{Resistensi Gulma Jajagoan terhadap Herbisida}

Gulma E. crus-galli jika tidak dikendalikan maka akan mengganggu pertumbuhan dan menurunkan produksi tanaman padi sawah. Dengan demikian diperlukan upaya pengendalian gulma yang tepat sasaran. Saat ini pengendalian gulma E. crus-galli yang digunakan petani lahan sawah masih dominan menggunakan herbisida kimiawi. Disisi lain penggunaan herbisida sintesis dapat menguntungkan petani dengan menghemat tenaga kerja dan biaya, namun disisi lain menimbulkan permasalahan baru yaitu terbentuknya biotip resisten yang susah untuk dikendalikan. Purba, (2009) menyatakan bahwa penggunaan herbisida dalam mengendalikan gulma dengan mode of action yang sejenis secara berulang-ulang pada periode waktu yang lama mengakibatkan resistensi.

Kasus E. crus-galli resisten herbisida pada pertanaman padi sawah pertama kali dilaporkan di Yunani oleh Giannopolitis \& Vassiliou, (1989) dan sudah berkembang ke beberapa negara di dunia (Tabel 1).

Tabel 1. Kasus E. crus-galli resisten beberapa herbisida pada pertanaman padi sawah di dunia dari tahun 1989-2019.

\begin{tabular}{clll}
\hline Tahun & \multicolumn{1}{c}{ Negara } & \multicolumn{1}{c}{ Herbisida } & \multicolumn{1}{c}{ Referensi } \\
\hline 1989 & Yunani & Propanil & Giannopolitis \& Vassiliou, 1989 \\
1994 & Pennsylvania & Propanil & Baltazar \& Smith, 1994 \\
1995 & Arkansas & Propanil & Carey et al., 1995 \\
1997 & Spanyol & Atrazine, Quinclorac & Lopez-Martinez et al., 1997 \\
2000 & Polandia & Triazine & Gadamski et al., 2000 \\
2002 & Sri Lanka & Propanil & Marambe \& Amarasinghe, 2002 \\
2007 & Brazil & Quinclorac & Valverde, 2007 \\
2009 & Korea Selatan & Cyhalofop-butyl & Im et al., 2009 \\
2010 & Philipina & Butachlor, propanil & Juliano et al., 2010 \\
2010 & Amerika Serikat & Propanil, quinclorac & Malik et al., 2010 \\
2010 & Malaysia & Propanil, quinclorac, & Rahman et al., 2010 \\
& & cyhalofop-butyl & \\
2011 & Amerika Serikat & Clomazone & Bagavathiannan et al., 2011 \\
2012 & Brazil & Quinclorac & Mortensen et al., 2012 \\
2012 & Arkansas & Bispyribac-sodium & Norsworthy et al., 2012 \\
2013 & Amerika Serikat & Imazamox, imazethapyr, & Riar et al., 2013 \\
2013 & Brazil & penoxsulam, bispyribac-sodium & \\
& & Imazethapyr, & Matzenbacher et al., 2013 \\
\hline
\end{tabular}




\begin{tabular}{|c|c|c|c|}
\hline 2014 & Amerika Serikat & $\begin{array}{l}\text { Imazethapyr, penoxsulam, } \\
\text { bispyribac-sodium, propanil, } \\
\text { quinclorac }\end{array}$ & Norsworthy et al., 2014 \\
\hline 2014 & Cina & $\begin{array}{l}\text { Fenoxaprop, bensulfuron, butachlor, } \\
\text { thiobencarb, molinate, quinclorac }\end{array}$ & Heap, 2015 \\
\hline 2015 & Jepang & Cyhalofop-butyl & Iwakami et al., 2015 \\
\hline 2016 & Cina & Penoxsulam & Chen et al., 2016 \\
\hline 2017 & Vietnam & Quinclorac & Le et al., 2017 \\
\hline 2018 & Brazil & Imazapyr + imazapic & Bonow et al., 2018 \\
\hline 2019 & Cina & Quinclorac & Qiong et al., 2019 \\
\hline 2019 & Uruguay & $\begin{array}{l}\text { Penoxsulam, imazapyr + imazapic, } \\
\text { quinclorac, propanil, } \\
\text { quinclorac + propanil }\end{array}$ & Marchesi \& Saldain, 2019 \\
\hline
\end{tabular}

\section{Pengelolaan Gulma Jajagoan Resisten-Herbisida}

Pengelolaan gulma biotip resisten-herbisida dapat menggunakan rotasi mode of action herbisida baik secara tunggal maupun campuran (Monaco et al., 2002). Knezevic et al., (2017) menyatakan bahwa gulma resisten herbisida yaitu mampu berkembang untuk survive setelah dikendalikan menggunakan herbisida. Penggunaan herbisida yang sama secara intensif dan berkelanjutan selama beberapa dekade terakhir akan menghasilkan evolusi gulma resisten herbisida. Chauhan \& Abugho, (2012) melaporkan bahwa herbisida campuran (penoxsulam+cyhalofop, fenoxaprop+ethoxysulfuron) dan herbisida tunggal (bispyribac-sodium) dapat menekan E. crus-galli lebih dari 90\%. Jabran et al., (2012) melaporkan herbisida tunggal (pendimethalin dosis $825 \mathrm{~g} \mathrm{b.a/ha,} \mathrm{bispyribac-sodium} 25 \mathrm{~g} \mathrm{b.a/ha,} \mathrm{dan}$ penoxsulam $15 \mathrm{~g} \mathrm{b.a/ha)} \mathrm{efektif} \mathrm{dalam} \mathrm{menekan} \mathrm{E.} \mathrm{crus-}$ galli masing-masing sebesar 69-75\%, 100\%, dan 53-65\% di areal padi sawah. Ntanos et al., (2000) melaporkan bahwa penggunaan herbisida tunggal cyhalofop-butyl efektif mengendalikan E. crus-galli $>90 \%$ pada areal padi sawah. Aparna et al., (2017) melaporkan bahwa herbisida bispyribac sodium sangat efektif mengendalikan E. crus-galli pada saat berdaun delapan. Cyhalofop butyl dan fenoxaprop-p-ethyl efektif menekan E. crus-galli pada saat berdaun empat dalam mengurangi persentase kelangsungan hidup.

\section{KESIMPULAN}

Karakteristik gulma E. crus-galli tergolong toleran pada berbagai kondisi iklim, memiliki jumlah biji yang melimpah mengakibatkan populasinya selalu hadir di areal persawahan dan menimbulkan kerugian produksi padi sawah jika tidak dikendalikan, bahkan gulma ini sudah resisten terhadap beberapa mode of action herbisida. Upaya pengelolaan gulma E. crus-galli resisten-herbisida menyarankan menggunakan rotasi mode of action herbisida baik secara tunggal atau campuran sebagai manajemen resisten dan diharapkan dapat memutus siklus resisten di areal persawahan.

\section{DAFTAR PUSTAKA}

Ahn, J. K., \& Chung, I. M. 2000. Allelopathic potential of rice hulls on germination and seedling growth of barnyardgrass. Agronomy Journal, 92(6), 11621167.

https://doi.org/10.2134/agronj2000.9261162x.
Alvarado, V., \& Bradford, K. J. 2002. A hydrothermal time model explains the cardinal temperatures for seed germination. Plant, Cell and Environment, 25(8), 1061-1069. https://doi.org/10.1046/j.13653040.2002.00894.x.

Aparna, K. K., Menon, M. V., \& Prameela, P. 2017. Efficacy of pre and post emergence herbicides on Echinochloa spp. Journal of Tropical Agriculture, 55(1), 91-95. http://jtropag.kau.in/index.php/ojs2/article/view/505.

Bagavathiannan, M. V., Norsworthy, J. K., Jha, P., \& Smith, K. 2011. Does resistance to propanil or clomazone alter the growth and competitive abilities of barnyardgrass (Echinochloa crus-galli)?. Weed science, 59(3), 353-358. https://doi.org/10.1614/WSD-10-00151.1.

Baltazar, A. M., \& Smith Jr, R. J. 1994. Propanil-resistant barnyardgrass (Echinochloa crus-galli) control in rice (Oryza sativa). Weed Technology, 8(3), 576581. https://doi.org/10.1017/S0890037X00039713.

Bhullar, M. S., Kumar, S., Kaur, S., Kaur, T., Singh, J., Yadav, R., Chauhan, B. S., \& Gill, G. 2016. Management of complex weed flora in dry-seeded rice. Crop Protection, 83, 20-26. https://doi.org/10.1016/j.cropro.2016.01.012.

Bonow, J. F. L., Lamego, F. P., Andres, A., \& Nogueira, E. 2018. Fitness of Echinochloa crusgalli var. mitis biotypes susceptible and resistant to imazapyr+ imazapic herbicide. Comunicata Scientiae, 9(4), 737-747.

https://dialnet.unirioja.es/servlet/articulo?codigo $=67$ 94630.

Carey, V. F., Hoagland, R. E., \& Talbert, R. E. 1995. Verification and distribution of propanil-resistant barnyardgrass (Echinochloa crus-galli) in Arkansas. Weed Technology, 9(2), 366-372. https://doi.org/10.1017/S0890037X00023496.

Chauhan, B. S., \& Abugho, S. B. 2012. Effect of growth stage on the efficacy of postemergence herbicides on four weed species of direct-seeded rice. The Scientific World Journal, 2012, 1-8. https://doi.org/10.1100/2012/123071.

Chen, G., Wang, Q., Yao, Z., Zhu, L., \& Dong, L. 2016. Penoxsulam-resistant barnyardgrass (Echinochloa crus-galli) in rice fields in China. Weed Biology and Management, $\quad 16(1)$, https://doi.org/10.1111/wbm.12086. 
Chin, D. V. 2001. Biology and management of barnyardgrass, red sprangletop and weedy rice. Weed Biology and Management, 1(1), 37-41. https://doi.org/10.1046/j.1445-6664.2001.00009.x.

Clay, S. A., Kleinjan, J., Clay, D. E., Forcella, F., \& Batchelor, W. 2005. Growth and fecundity of several weed species in corn and soybean. Agronomy Journal, 97(1), 294-302. https://doi.org/10.2134/agronj2005.0294a.

Eberhardt, D. S., Oliveira Neto, A. M., Noldin, J. A., \& Vanti, R. M. 2016. Barnyardgrass with multiple resistance to synthetic auxin, ALS and ACCase inhibitors. Planta Daninha, 34(4), 823-832. https://doi.org/10.1590/s010083582016340400023

Fischer, A. J., Ateh, C. M., Bayer, D. E., \& Hill, J. E. 2000. Herbicide-resistant Echinochloa oryzoides and E. phyllopogon in California Oryza sativa fields. Weed Science, 48(2), 225-230. https://doi.org/10.1614/00431745(2000)048[0225:HREOAE]2.0.CO;2.

Gadamski, G., Ciarka, D., Gressel, J., \& Gawronski, S. W. 2000. Negative cross-resistance in triazineresistant biotypes of Echinochloa crus-galli and Conyza canadensis. Weed Science, 48(2), 176-180. https://doi.org/10.1614/0043-

1745(2000)048[0176:NCRITR]2.0.CO;2.

Gallandt, E. R. 2006. How can we target the weed seedbank?. Weed Science, 54(3), 588-596. https://doi.org/10.1614/WS-05-063R.1.

Gealy, D. R., Wailes, E. J., Estorninos, L. E., \& Chavez, R. S. C. 2003. Rice cultivar differences in suppression of barnyardgrass (Echinochloa crusgalli) and economics of reduced propanil rates. Weed 5cience, 51(4), 601-609. https://doi.org/10.1614/00431745(2003)051[0601:RCDISO]2.0.CO;2.

Giannopolitis, C. N., \& Vassiliou, G. 1989. Propanil tolerance in Echinochloa crus-galli (L.) Beauv. International Journal of Pest Management, 35(1), 67. https://doi.org/10.1080/09670878909371310.

Gibson, K. D., Fischer, A. J., Foin, T. C., \& Hill, J. E. 2002. Implications of delayed Echinochloa spp. germination and duration of competition for integrated weed management in water-seeded rice. Weed Research, 42(5), 351-358. https://doi.org/10.1046/j.1365-3180.2002.00295.x.

Guntoro, D., Chozin, M. A., Santosa, E., Tjitrosemito, S., \& Burhan, A. H. 2009. Kompetisi antara ekotipe Echinochloa crus-galli pada beberapa tingkat populasi dengan padi sawah. Jurnal Agronomi Indonesia, 37(3), 202-208. https://doi.org/10.24831/jai.v37i3.1236.

Heap I. M. 2015. International survey of herbicide resistant weeds. www.weedscience.org.

Im, S. H., Park, M. W., Yook, M. J., \& Kim, D. S. 2009. Resistance to ACCase inhibitor cyhalofop-butyl in Echinochloa crus-galli var. crus-galli collected in Seosan, Korea. The Korean Journal of Weed Science, 29(2), 178-184. http://koreascience.or.kr/article/JAKO20091010342 6033.page.
Iwakami, S., Hashimoto, M., Matsushima, K. I., Watanabe, H., Hamamura, K., \& Uchino, A. 2015. Multiple-herbicide resistance in Echinochloa crusgalli var. formosensis, an allohexaploid weed species, in dry-seeded rice. Pesticide Biochemistry and Physiology, 119, 1-8 https://doi.org/10.1016/j.pestbp.2015.02.007.

Jabran, K., Farooq, M., Hussain, M., Khan, M. B., Shahid, M., \& Dong-Jin, L. 2012. Efficient weeds control with penoxsulam application ensures higher productivity and economic returns of direct seeded rice. International Journal of Agriculture and Biology, 14(6), 901-907.

Juliano, L. M., Casimero, M. C., \& Llewellyn, R. 2010. Multiple herbicide resistance in barnyardgrass (Echinochloa crus-galli) in direct-seeded rice in the Philippines. International Journal of Pest Management, 56(4), 299-307. https://doi.org/10.1080/09670874.2010.495795.

Knezevic, S. Z., Jhala, A., \& Gaines, T. 2017. Herbicide resistance and molecular aspects. Encyclopedia of Applied Plant Sciences $2^{\text {nd }}$ Edition. 3, 455-458.

Le, D., Nguyen, C. M., Mann, R. K., Yerkes, C. N., \& Kumar, B. V. N. 2017. Genetic diversity and herbicide resistance of 15 Echinochloa crus-galli populations to quinclorac in Mekong Delta of Vietnam and Arkansas of United States. Journal of Plant Biotechnology, 44(4), 472-477. https://doi.org/10.5010/JPB.2017.44.4.472.

Li, G., Xu, M. F., Chen, L. P., Cai, L. M., Bai, L. Y., \& Wu, C. X. 2016. A novel EcGH3 gene with a different expression pattern in quinclorac-resistant and susceptible barnyardgrass (Echinochloa crusgalli). Plant Gene, 5, 65-70. https://doi.org/10.1016/j.plgene.2015.12.002.

Lopez-Martinez, N., Marshall, G., \& De Prado, R. 1997. Resistance of barnyardgrass (Echinochloa crus-galli) to atrazine and quinclorac. Pesticide Science, 51(2), 171-175. https://doi.org/10.1002/(SICI)10969063(199710)51:2\%3C171::AIDPS612\%3E3.0.CO;2-7.

Malik, M. S., Burgos, N. R., \& Talbert, R. E. 2010. Confirmation and control of propanil-resistant and quinclorac-resistant barnyardgrass (Echinochloa crus-galli) in rice. Weed Technology, 24(3), 226233. https://doi.org/10.1614/WT-09-053.1.

Marambe, B., \& Amarasinghe, L. 2002. Propanil-resistant barnyardgrass [Echinochloa crus-galli (L.) Beauv.] in Sri Lanka: Seedling growth under different temperatures and control. Weed Biology and Management, 2(4), 194-199. https://doi.org/10.1046/j.1445-6664.2002.00068.x.

Marchesi, C., \& Chauhan, B. S. 2019. The efficacy of chemical options to control Echinochloa crus-galli in dry-seeded rice under alternative irrigation management and field layout. Crop Protection, 118 72-78. https://doi.org/10.1016/j.cropro.2018.12.016.

Marchesi, C., \& Saldain, N. E. 2019. First report of herbicide-resistant Echinochloa crus-galli in Uruguayan rice fields. Agronomy, 9(12), 790-808. https://doi.org/10.3390/agronomy9120790. 
Matzenbacher, F. D. O., Kalsing, A., Menezes, V. G., Barcelos, J. A. N., \& Merotto Junior, A. 2013. Rapid diagnosis of resistance to imidazolinone herbicides in barnyardgrass (Echinochloa crusgalli) and control of resistant biotypes with alternative herbicides. Planta Daninha, 31(3), 645$656 . \quad$ https://doi.org/10.1590/S010083582013000300016.

Maun, M. A., \& Barrett, S. C. H. 1986. The biology of canadian weeds.: 77. Echinochloa crus-galli (L.) Beauv. Canadian Journal of Plant Science, 66(3), 739-759. https://doi.org/10.4141/cjps86-093.

Monaco, T. J., Weller, S. C., \& Ashton, F. M. 2002. Weed science: principles and practices. John Wiley \& Sons.

Mortensen, D. A., Egan, J. F., Maxwell, B. D., Ryan, M. R., \& Smith, R. G. 2012. Navigating a critical juncture for sustainable weed management. BioScience, $62(1)$, 75-84. https://doi.org/10.1525/bio.2012.62.1.12.

Norsworthy, J. K., Ward, S. M., Shaw, D. R., Llewellyn, R. S., Nichols, R. L., Webster, T. M., \& Witt, W. W. 2012. Reducing the risks of herbicide resistance: best management practices and recommendations. Weed Science, 60(SP1), 31-62. https://doi.org/10.1614/WS-D-11-00155.1.

Norsworthy, J. K., Wilson, M. J., Scott, R. C., \& Gbur, E. E. 2014. Herbicidal activity on acetolactate synthase-resistant barnyardgrass (Echinochloa crus-galli) in Arkansas, USA. Weed Biology and Management, $14(1)$, $50-58$. https://doi.org/10.1111/wbm.12032.

Ntanos, D. A., Koutroubas, S. D., \& Mavrotas, C. 2000. Barnyardgrass (Echinochloa crus-galli) control in water-seeded rice (Oryza sativa) with cyhalofopbutyl 1. Weed Technology, 14(2), 383-388. https://doi.org/10.1614/0890037X(2000)014[0383:BECGCI]2.0.CO;2.

Purba, E. 2009. Keanekaragaman herbisida dalam pengendalian gulma mengatasi populasi gulma resisten dan toleran herbisida. Universitas Sumatera Utara

Pusat Data dan Sistem Informasi Pertanian. 2019. Buletin konsumsi pangan tahun 2019. Kementerian Pertanian, Jakarta. 107 p.

Qiong, P., Heping, H., Xia, Y., Lianyang, B., Qin, Y., \& Powles, S. B. 2019. Quinclorac Resistance in Echinochloa crus-galli from China. Rice Science, 26(5), 300-308. https://doi.org/10.1016/j.rsci.2019.08.004.

Rahman, M. M., Sahid, I. B., \& Juraimi, A. S. 2010. Study on resistant biotypes of Echinochloa crusgalli in Malaysia. Australian Journal of Crop Science, 4(2), 107-115. https://search.informit.org/doi/abs/10.3316/informit .982579140697154 .

Rao, A. N., Johnson, D. E., Sivaprasad, B., Ladha, J. K., \& Mortimer, A. M. 2007. Weed management in direct-seeded rice. Advances in Agronomy, 93, 153-255. https://doi.org/10.1016/S00652113(06)93004-1.

Riar, D. S., Norsworthy, J. K., Srivastava, V., Nandula,
V., Bond, J. A., \& Scott, R. C. 2013. Physiological and molecular basis of acetolactate synthaseinhibiting herbicide resistance in barnyardgrass (Echinochloa crus-galli). Journal of Agricultural and Food Chemistry, 61(2), 278-289. https://doi.org/10.1021/jf304675j.

Saito, K., Azoma, K., \& Rodenburg, J. (2010). Plant characteristics associated with weed competitiveness of rice under upland and lowland conditions in West Africa. Field Crops Research, 116(3), 308-317. https://doi.org/10.1016/j.fcr.2010.01.008.

Singh, M., Bhullar, M. S., \& Chauhan, B. S. 2015. Influence of tillage, cover cropping, and herbicides on weeds and productivity of dry direct-seeded rice. Soil and Tillage Research, 147, 39-49. https://doi.org/10.1016/j.still.2014.11.007.

Soerjani, M., Kostermans, A. J. G., \& Tjitrosoepomo, G. 1987. Weeds of rice in Indonesia. Balai Pustaka.

Travlos, I. S., Economou, G., \& Kanatas, P. J. 2011. Corn and barnyardgrass competition as influenced by relative time of weed emergence and corn hybrid. Agronomy Journal, 103(1), 1-6. https://doi.org/10.2134/agronj2010.0245.

Valverde, B. E. 2007. Status and management of grassweed herbicide resistance in Latin America. Weed Technology, 21(2), 310-323. https://doi.org/10.1614/WT-06-097.1.

Van Devender, T. R., Felger, R. S., \& Búrquez, A. 1997. Exotic plants in the Sonoran Desert region, Arizona and Sonora. In Proceedings of the California Exotic Pest Plant Council Symposium. California.

Wilson, M. J., Norsworthy, J. K., Scott, R. C., \& Gbur, E. E. 2014. Program approaches to control herbicideresistant barnyardgrass (Echinochloa crus-galli) in midsouthern United States rice. Weed Technology, 28(1), 39-46. https://doi.org/10.1614/WT-D-1300062.1.

Yang, X., Zhang, Z., Gu, T., Dong, M., Peng, Q., Bai, L., \& Li, Y. 2017. Quantitative proteomics reveals ecological fitness cost of multi-herbicide resistant barnyardgrass (Echinochloa crus-galli L.). Journal of Proteomics, 150, 160-169. https://doi.org/10.1016/j.jprot.2016.09.009.

Zhu, J., Wang, J., DiTommaso, A., Zhang, C., Zheng, G., Liang, W., Islam, F., Yang, C., Chen, X., \& Zhou, W. 2018. Weed research status, challenges, and opportunities in China. Crop Protection, 134, 104449. https://doi.org/10.1016/j.cropro.2018.02.001. 